\section{edmundo vasconcelos}

\title{
OS DESAFIOS NO GERENCIAMENTO DE \\ LEITOS: COMO OTIMIZAR OS LEITOS HOSPITALARES ATRAVÉS DE ESTRATÉGIAS MULTIDISCIPLINARES
}

\section{Carolina Kitade Velloso}

\section{INTRODUÇÃO}

O papel do Gerenciamento de Leitos dentro dos hospitais é de grande importância, pois busca a otimização dos leitos já existentes através da excelência dos processos hospitalares, com ações multidisciplinares voltadas ao fluxo do paciente. A utilização dos leitos de forma adequada fornece mais serviços com os mesmos ou menos recursos, garantindo a sustentabilidade do negócio, satisfação e segurança aos clientes.

\section{OBJETIVO}

Demonstrar as estratégias utilizadas na busca por processos mais eficientes e recursos mais otimizados.

\section{METODOLOGIA}

O estudo foi realizado no Hospital Edmundo Vasconcelos entre 2014 a 2018, onde analisou-se a alta hospitalar e os processos relacionados ao fluxo do paciente. Foram monitorados a assertividade das altas hospitalares, o tempo de saída do paciente, a variação na ocupação dos leitos e o atraso cirúrgico devido demora para internação. Para melhorar a performance da equipe, foram adotadas estratégias multidisciplinares, como a estruturação do plano terapêutico, a priorização da visita médica nos pacientes com previsão de alta e a adequação da logística dos cuidados a estes pacientes, agilizando assim todo o processo de saída hospitalar.

\section{RESULTADO}

Feito a implantação das ações, observamos uma melhora nos resultados de 2018. Com a priorização da visita médica aos pacientes com previsão de alta e a estruturação do plano terapêutico, foi possível o planejamento antecipado das ações multidisciplinares do pós-alta, impactando nos indicadores de assertividade das altas hospitalares, tempo de saída do paciente e variação na ocupação dos leitos, o que foi essencial para o atendimento da demanda eletiva de pacientes que chegam nos primeiros horários da manhã para procedimentos cirúrgicos.

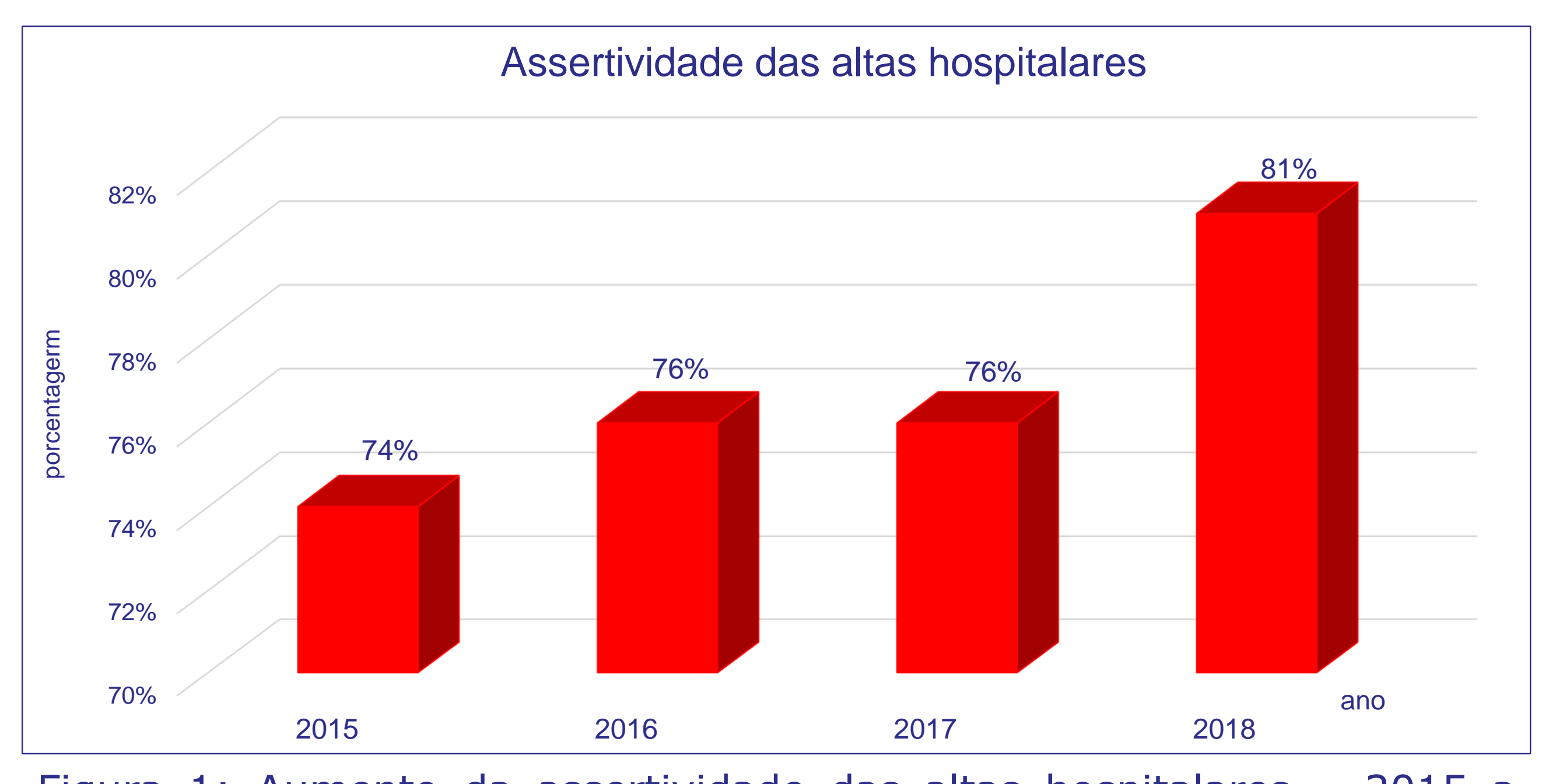

Em relação à variação da ocupação dos leitos, observamos um predomínio na internação dos pacientes nos primeiros horário da manhã em ambos os anos. Já em relação às altas, em 2018 há uma maior quantidade de pacientes com saída nos horários das $08 \mathrm{~h} 00$ às $10 \mathrm{~h} 00$, totalizando $32 \%$ das altas hospitalares no período analisado.

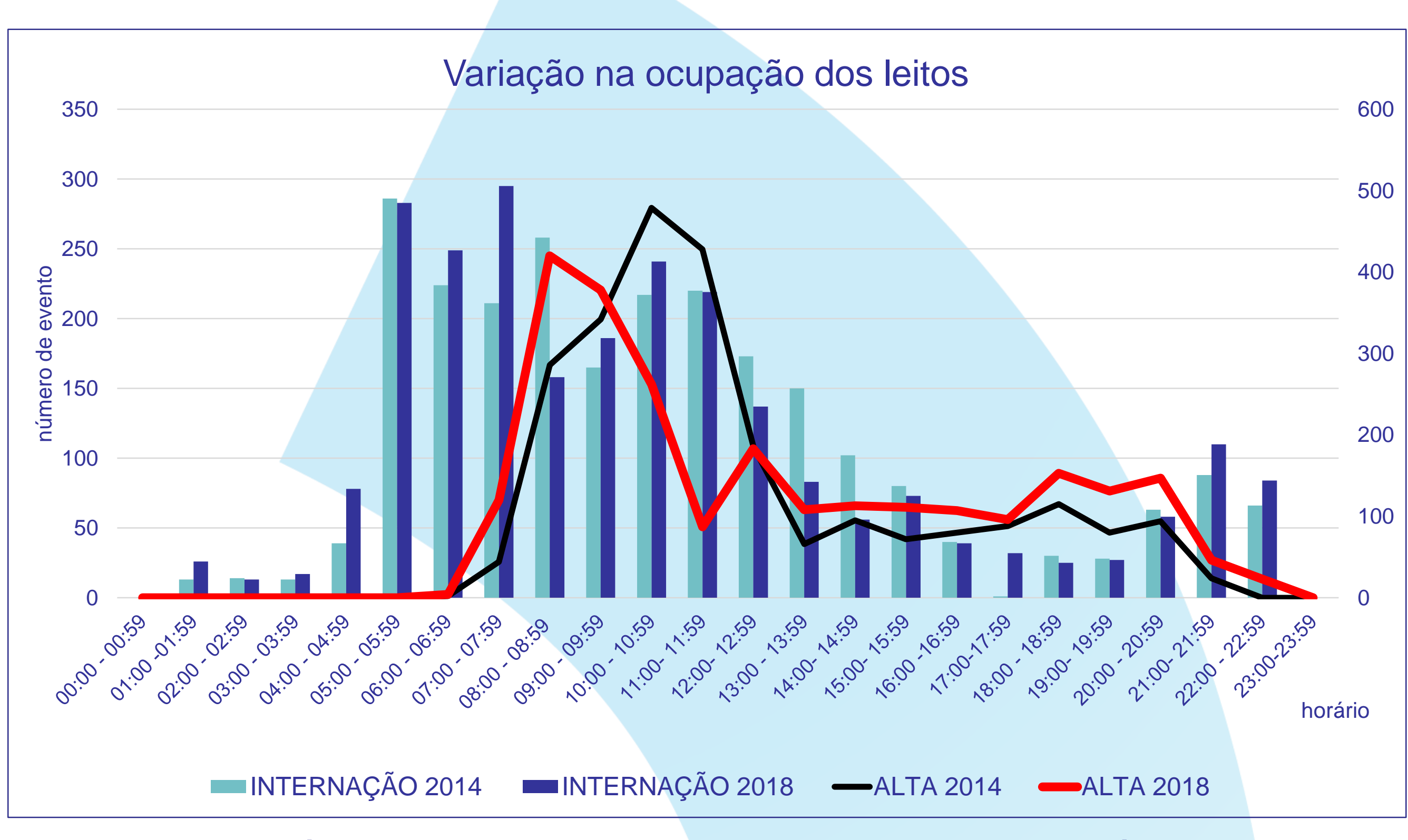

Figura 2: Horário da internação dos pacientes $x$ horário das altas hospitalares - 2014 e 2018

Com isso, houve a repercussão no indicador de atraso cirúrgico devido demora para a internação, pois havia uma média de $26 \%$ de atraso das cirurgias devido falta de leito para as internações, e em 2018 conseguimos praticamente resolver esse apontamento no Hospital.

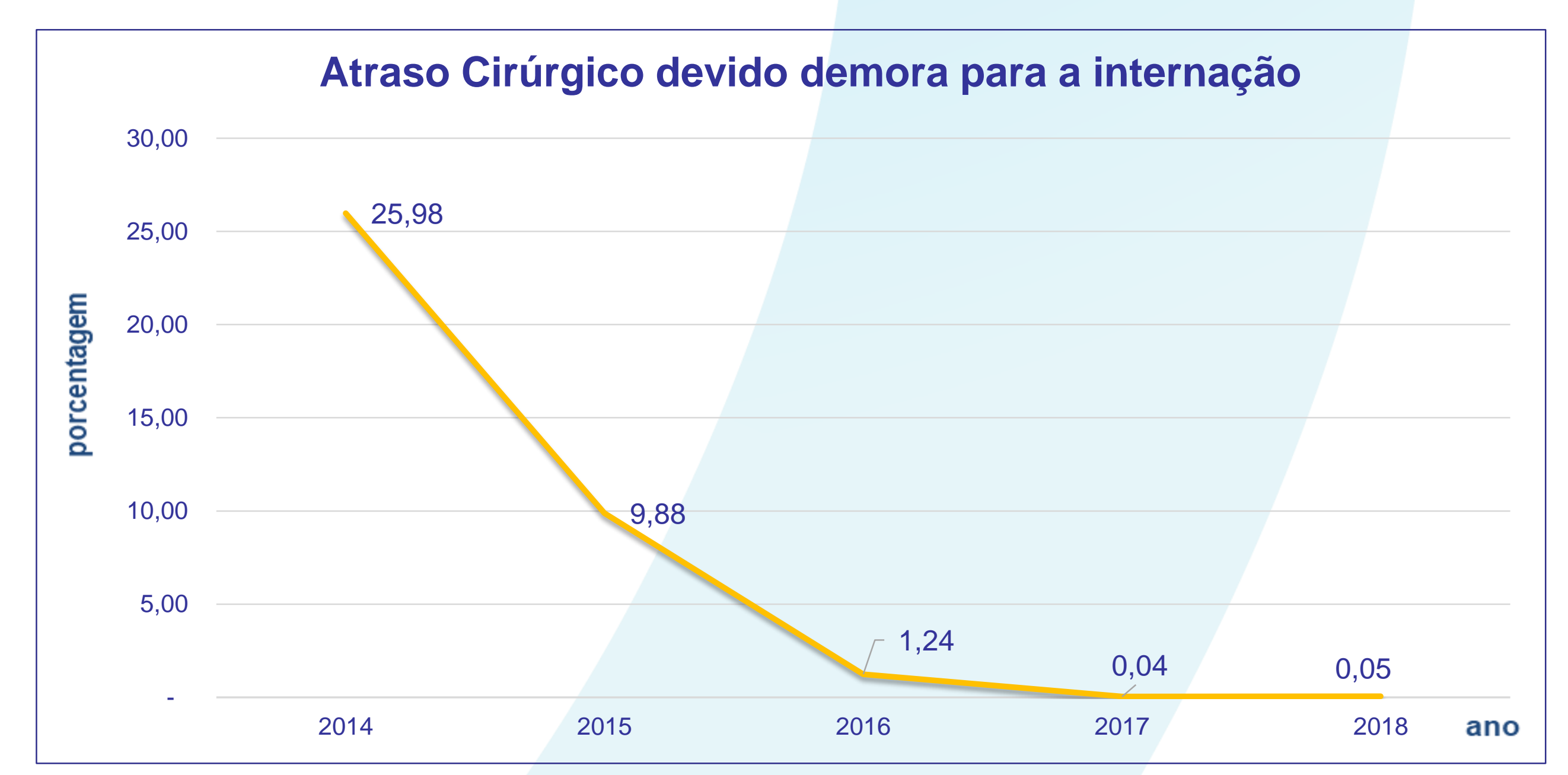

Figura 3: Redução no atraso cirúrgico devido demora para a internação 2014 e 2018

\section{CONCLUSÃO}

Com os resultados atingidos, pudemos observar uma efetiva otimização dos leitos devido às melhores práticas assistenciais, permitindo o hospital a atender um número maior de pacientes sem a necessidade de aumento do número de leitos, trabalhando exclusivamente a otimização dos processos através de estratégias multidisciplinares.

\section{REFERÊNCIA BIBLIOGRÁFICA}

The Advisory Board International. Manual de estratégia de altas: como gerar capacidade eliminando atrasos no final da hospitalização. Washington: Advisory Board Research. 2013

The Advisory Board International. Next generation capacity management: collaborating for clinically appropriate and efficient inpatient throughput. Washington: Advisory Board Research. 2010 